\title{
Mother/child bond in mothers of overweight and eutrophic children: depression and socioeconomic factors
}

\author{
Vínculo mãe/filho de mães de crianças com excesso de peso e eutróficas: depressão e \\ fatores socioeconômicos
}

\author{
Patricia Vieira Spada ${ }^{1}$, Maria Arlete Meil Escrivão², Fernando José de Nóbrega ${ }^{3}$, Yára Juliano ${ }^{4}$
}

\begin{abstract}
Objective: To verify the presence of depression, age, level of schooling, occupation, marital status, number of children and nutritional status (maternal and of the child) in mothers of overweight and eutrophic children and relate the data to mother/child bonding. Methods: A total of 120 mothers of children aged up to 10 years participated; 30 of them were overweight and 30 were eutrophic (low-income bracket); 30 were overweight and 30 eutrophic (high-income bracket). The control group was composed of eutrophic children paired according to sex, age, level of schooling, and social condition. Data collection was made through interviews. The assessment instruments were: Mother/ Child Bonding Assessment Protocol and Beck Depression Inventory. The nutritional classification was defined by calculation of the body mass index, as per the curves of the World Health Organization. For statistics, McNemar, $\chi^{2}$, and Fisher's exact tests were used. A $5 \%$ level of rejection of the null hypothesis was set. Results: There was no significant result between mother/child bonding and the variables studied, or between the presence of depression and level of schooling, marital status, occupation, and maternal nutritional status. Nevertheless, mothers of eutrophic children (high-income bracket) showed less depression than mothers of eutrophic children (low-income bracket). Mothers with three or more children displayed more depression than mothers with less than three children. Mothers under 30 years of age showed more depression than mothers aged 30 years or older. Conclusion: There was no significant result between mother/child bonding and the variables studied, but the bond was compromised in all mothers of the sample. There was a significant result regarding the presence of depression.
\end{abstract}

Keywords: Mother-child relations; Maternal age; Depression

\section{RESUMO}

Objetivo: Verificar presença de depressão, idade, escolaridade, ocupação, condição marital, número de filhos e condição nutricional (materna e da criança) em mães de crianças com excesso de peso e eutróficas e relacionar dados ao vínculo mãe/filho. Métodos: Participaram 120 mães de crianças (até 10 anos): 30 com excesso de peso e 30 eutróficas (baixa condição econômica); 30 com excesso de peso e 30 eutróficas (alta condição econômica). 0 Grupo Controle foi composto por crianças eutróficas pareadas por sexo, idade, escolaridade e condição social. A coleta de dados foi realizada por meio de entrevistas. Os instrumentos para avaliação foram: Protocolo de Avaliação do Vínculo Mãe/Filho, Inventário Beck de Depressão. A classificação nutricional foi definida pelo cálculo do índice de massa corporal, de acordo com as curvas da Organização Mundial de Saúde. Para estatística, foram utilizados os testes de McNemar, $\chi^{2}$ e exato de Fisher. Fixou-se em 5\% o nível de rejeição da hipótese de nulidade. Resultados: Não houve resultado significante entre vínculo mãe/filho e as variáveis estudadas, bem como entre presença de depressão e escolaridade, condição marital, ocupação e condição nutricional materna. Entretanto, mães de crianças eutróficas (alta condição econômica) apresentaram menos depressão que mães de crianças eutróficas (baixa condição econômica). Mães com 3 filhos ou mais apresentaram mais depressão que mães com menos de 3 filhos. Mães com menos 30 anos apresentaram mais depressão que mães com 30 anos ou mais. Conclusão: Não houve resultado significante entre vínculo mãe/filho e as variáveis estudadas, mas seu comprometimento foi alto em todas as mães da amostra. Houve resultado significante de presença de depressão.

Descritores: Relações mãe-filho; Idade materna; Depressão

\footnotetext{
Study carried out at Department of Graduate Courses in Nutrition, Escola Paulista de Medicina, Universidade Federal de São Paulo - UNIFESP, Sao Paulo (SP), Brazil; Outpatient Clinics - Einstein in

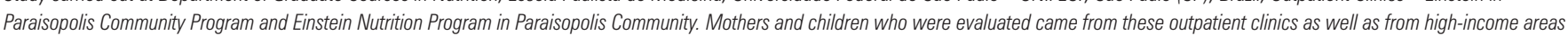
in the city of Sao Paulo (SP), Brazil.

'Graduate Program in Nutrition, Escola Paulista de Medicina, Universidade Federal de São Paulo - UNIFESP, Sao Paulo (SP), Brazil.

${ }^{2}$ Obesity Sector, Nutrition Division, Department of Pediatrics, Escola Paulista de Medicina, Universidade Federal de São Paulo - UNIFESP, Sao Paulo (SP), Brazil.

${ }^{3}$ Coordinator of Research on Human Nutrition, Instituto Israelita de Ensino e Pesquisa Albert Einstein - IIEPAE, Sao Paulo (SP),

${ }^{4}$ Faculdade de Medicina, Universidade de Santo Amaro - UNISA, Sao Paulo (SP), Brazil.


support of the Coordination for the Improvement of Higher Education Personnel (CAPES).

Corresponding author: Patricia Vieira Spada - Rua Júlio Diniz, 145, apto. 181 - Vila Olímpia - CEP 04547090 - Sao Paulo (SP), Brazil - Tel.: $113845-5598$ - E-mail: patspada@ig.com.br

Received: Jul 27, 2010 - Accepted: Feb 08, 2011

The authors declare there is no conflict of interest.
} 


\section{INTRODUCTION}

The mother/child bond has been considered of primary importance for the overall development of a child ${ }^{(1)}$. It is in the first years of life that the foundation that will support the pillars of the child's personality and character are formed (2).

Spitz ${ }^{(3)}$ showed, by means of practical observations of the clinical pictures of a statistically significant number of children, that inappropriate and/or insufficient maternal attitudes could generate, in their children, conditions ranging from coma in the newborn to marasmus and death, evidencing the serious physical and psychic damage resulting from the privation of elements vital for survival, in other words, maternal affection. He highlighted the influence of maternal depression on the etiology of various physical and emotional diseases in the child.

Klaus and Kennel (4) emphasized that the bond of affection between parents and their baby would be the basis for future relationships of the child, and that these would be influenced by the strength and quality of this bond. They acknowledge, in their extensive observation work of parents/babies a few indicators that may strengthen, alter, distort, or compromise the formation and quality of this bond. Other authors added that equally important aspects should be taken into consideration, such as the child's temperament, its "affective place" within the family dynamics, number of siblings, the family's socioeconomic condition, and maturity of the mother, among others ${ }^{(5-8)}$.

In Brazil, it is important to point out the work done by Nóbrega et al. (9) about strengthening the mother/ child bond. Nóbrega et al. were initially dedicated to creating the first Pediatric Practice Obesity Outpatient Clinic, at the Department of Pediatrics of the Medical School of Botucatu, Universidade Estadual Paulista "Júlio de Mesquita Filho", in 1969, and later, to outpatient clinics for malnourished, low-height, and obese patients, breastfeeding and clinical nutrition of the extinct Núcleo de Nutrição, Alimentação e Desenvolvimento Infantil (NUNADI) [Center of Child Nutrition, Diet and Development], of the Secretariat of Health of the State of Sao Paulo. On this occasion, he and his team created a unique instrument that is systematic, objective, and easy to use so that new indicators of compromised mother/child bonding which have been observed by professionals - might be identified, grouped, and organized. It was composed of 18 items divided into groups referring to past and current history of the mother (her childhood, parental models, personal, professional, and conjugal life, family environment, and gestation), quality of the mother/ infant relationship (birth, maternity, breastfeeding, and first relations), and issues specifically related to the baby (first days of life, health conditions, and characteristics), in which, in order to facilitate reading and understanding of the terms, all items were strictly defined so that this instrument could be used by other professionals as well, after training, besides psychologists.

In the year 2000, with the establishment of the Einstein Nutrition Program in the Paraisópolis Community (PENC-P), in the city of Sao Paulo, coordinated by professor Nóbrega - with the objective of identifying risk factors for malnutrition and intervening with an interdisciplinary team, treating the mother/ child pair, the Mother/Child Bonding Assessment Protocol was updated to include 16 items. Based on its statistical study and validation ${ }^{(10)}$, it now has 13 items with respective subitems ${ }^{(11)}$. Due to its great usefulness and the fact that it can be applied in Primary Healthcare Units (UBS), hospitals, clinics, daycare centers, preschools, and outpatient clinics, it was adopted and utilized by other authors in several investigations performed at the Federal Universities of the states of Sao Paulo (UNIFESP), Minas Gerais (UFMG), Rio de Janeiro (UFRJ), Espirito Santo (UFES), Santa Catarina (UFSC), and at the Universidade de São Paulo (USP), as well as in other studies that are still ongoing, including overseas.

It is important to point out that the application of this instrument in pediatric outpatient clinics is of vital importance, since, as a primary care service, its aim is to promote health both of the mother and of the child, allowing early detection of possible failures in the mother/child bond, which could lead to significant deficits in the child global development. Therefore, there are no scientific studies in literature covering the quality of the mother/child bond, since this instrument was created based on the abovementioned experiences.

Consequently, this study proposed the identification of the conditions in which there may be a compromise of the bond between mother and child, in order to prevent damage and strengthen the bond, considering that the quality of the affection between the members of this pair may instigate, maintain, and/or contribute towards various nutritional and affective disorders, leading to significant impairment of the child's overall development.

\section{OBJECTIVE}

To verify, in the mothers, factors such as presence of depression, economic conditions, age, level of schooling, occupation, marital condition, number of children, and nutritional status of the pair, besides relating these factors to the mother/child bond. 


\section{METHODS}

This is a cross-sectional quantitative study in which 120 mothers of children aged under 10 years participated.

The mothers were divided into four groups: 30 mothers of overweight children from a low-income bracket; 30 mothers of eutrophic children from a lowincome bracket; 30 mothers of overweight children from a high-income bracket; and 30 mothers of eutrophic children from a high-income bracket.

Of the total 120 mothers in the sample, 60 were a part of the control group, which was divided into 30 mothers of eutrophic children from a low-income bracket and 30 mothers of eutrophic children from a high-income bracket. The control group was paired as to sex, age, level of schooling, and economic condition.

Overweight and eutrophic mothers of low-income bracket were interviewed by the researcher of this study at the outpatient clinic of the PEC-P, located in the city of Sao Paulo ${ }^{(12)}$. Adjacent to this outpatient clinic, the Einstein Nutrition Program in Paraisopolis Community (PENC-P) operated, which treated mothers and children with nutritional risks referred to the institution after identification and capture of data made by healthcare agents of the community itself through home visits and other methods. At this location, the following services were offered: specialized multiprofessional care, orientation, treatment and referral, whenever necessary.

The first 30 eutrophic mothers from high-income bracket who were a part of the control group were recruited by the researcher at a swimming school in the neighborhood of Vila Nova Conceicao, in the city of Sao Paulo (SP State), and the other mothers, by means of snowballing ${ }^{(13)}$ - a sampling technique that consists of indications on the part of the subject themselves for the capture of additional subjects, and which includes those with a rich information potential. The interviews of these groups were carried out in the homes of the mothers. In the same way, 30 mothers of overweight children from a high-income bracket were captured and interviewed.

The inclusion criteria for mothers of overweight children coming from low-income bracket were mothers of children up to 10 years of age, who were overweight, resided in the Paraisopolis community, and who presented with no underlying diseases.

The inclusion criteria for mothers of eutrophic children from low-income bracket were mothers of children up to 10 years of age who were eutrophic, healthy, resided in the Paraisopolis community, and who presented with no chronic diseases.

The inclusion criteria for mothers of overweight children from high-income bracket were mothers who lived in high-class regions of the city of Sao Paulo, owned their own vehicle, had overweight children up to 10 years of age who studied at private schools and presented with no underlying diseases.

The inclusion criteria for mothers of eutrophic children from high-income bracket were mothers who lived in high-class regions of the city of Sao Paulo, owned their own vehicle, and whose children up to 10 years of age were eutrophic, healthy, studied at private schools, and presented with no chronic diseases.

Non-inclusion criteria for both economic and nutritional status were children who were overweight due to endogenous causes, eutrophic children with chronic diseases, and mothers presenting with serious mental disorders.

Data were collected by the researcher by means of interviews carried out during the period from March 2004 to July 2006. The interviews included the application of the Mother/Child Bonding Assessment Protocol $^{(11)}$, Beck Depression Inventory ${ }^{(14)}$, and nutrition classification $^{(15)}$.

The instruments used for the assessment of the mother/child bond ${ }^{(11)}$ and of the presence of depression - Beck Depression Inventory ${ }^{(13)}$ were:

- Mother/Child Bonding Assessment Protocol (11) composed of 13 questions with yes/no answers, in which "yes" was the answer positive for the presence of an attribute or indicator of a weak bond. Adding up the "yes" responses, a score is obtained, which may vary from 1 to 13 . A positive classification for a weak bond occurs when the number of positive answers $\geq 5$. The instrument was validated with the objective of making it reliable and useful for other healthcare professionals, besides psychologists, who should be trained for its use;

- the Beck Depression Inventory ${ }^{(14)}$ comprises 21 items, with intensity varying from 0 to 3 , in reference to symptoms and attitudes, such as sadness, pessimism, feeling of failure, lack of satisfaction, feeling of guilt, feeling of punishment, self-depreciation, selfaccusation, suicidal ideas, crying spells, irritability, social retraction, indecision, body image distortion, inhibition for work, sleep disturbances, fatigue, loss of appetite, weight loss, somatic preoccupations, and decreased libido. This inventory may be self-applied, used individually, or in a group. The total sum of these scores shows the degree of intensity of depression. It is recommended that the term "depression" be used only for individuals whose scores are over 20. In this study, this value was the cutoff point.

For measurements of the mothers' and children's weights, a Health-O-Meter ${ }^{\circledR}$ digital scale was used with a $150-\mathrm{kg}$ capacity and a variation of $0.1 \mathrm{~kg}$. For measurements of height, a non-elastic measuring tape was used, with an extension of $2 \mathrm{~m}$, divided into centimeters 
and subdivided into millimeters, with variations of $0.5 \mathrm{~cm}$, affixed to a smooth wall with no baseboard. Mothers and children were evaluated with heels together, no shoes, and wearing light clothing. The values collected were written down on the identification chart of each mother/ child pair. The nutritional classification of all mothers was made using the body mass index (BMI) calculation as weight $(\mathrm{kg}) /$ height $^{2}\left(\mathrm{~m}^{2}\right)$, using the cutoff points proposed by the World Health Organization (WHO) ${ }^{(15)}$.

Since the difference between the cutoff points was small and there were no children with morbid obesity, it was decided to pool the children with excess weight and obesity into one single group, characterized, in this study, as the group of overweight children. The same procedure was used with the mothers.

\section{Statistical method}

Data were analyzed quantitatively by means of statistical techniques and presented as tables, considering the interpretation criteria for the test results.

For analysis of the results, $\chi^{2}$ or Fisher's exact tests were used (16) in order to detect association among the variables studied; the McNemar test ${ }^{(16)}$ was used to confront the groups studied relative to quantitative variables.

The level of rejection of the null hypothesis was set at 0.05 or $5 \%$, with an asterisk marking the significant values.

All mothers signed informed consent forms. This study was approved by the Ethics Committee of the Escola Paulista de Medicina of UNIFESP and by the Instituto de Ensino e Pesquisa do Hospital Israelita Albert Einstein (IIEPAE).

\section{RESULTS}

According to Table 1, mothers of eutrophic children from high-income bracket displayed less depression than mothers of eutrophic children from low-income bracket.

Table 2 shows that mothers with three or more children showed more depression than mothers with less than three children. Additionally, mothers under the age of 30 years showed more depression than did those 30 years of age or older (Table 3). According to Table 4, all mothers showed greater compromise in bonding than the presence of depression.

Although the bond proved to be hindered in all mothers of the sample, there was no statistically significant result among the mother/child bond and the variables analyzed. Similarly, there was no statistically significant result between the presence of depression and level of schooling, marital condition, occupation, and maternal nutritional status.

Table 2. Study of the association of mothers of eutrophic and overweight children of low and high-income brackets according to number of children $(<3$; $\geq 3$ ) and the result of the Beck Depression Inventory.

\begin{tabular}{lcccc}
\hline \multirow{2}{*}{ Number of children } & \multicolumn{4}{c}{ Depression } \\
\cline { 2 - 5 } & with & w/o & Total & \% with \\
\hline$<3$ & 8 & 65 & 73 & 11.0 \\
$\geq 3$ & 17 & 30 & 47 & 36.2 \\
Total & 25 & 95 & 120 & 47.2 \\
\hline
\end{tabular}

Chi-square test

$\chi^{2}=11.019^{*}$

Table 3. Study of the association of mothers of eutrophic and overweight children of low and high-income brackets according to age ( $<30 ; \geq 30$ years) and the result of the Beck Depression Inventory.

\begin{tabular}{lcccc}
\hline \multirow{2}{*}{ Maternal age } & \multicolumn{4}{c}{ Depression } \\
\cline { 2 - 5 } & with & w/o & Total & $\%$ with \\
\hline$<30$ & 12 & 10 & 22 & 54.5 \\
$\geq 30$ & 13 & 85 & 98 & 13.2 \\
\hline Total & 25 & 95 & 120 & 67.7 \\
\hline
\end{tabular}

Fisher's exact test

$p=0.000094^{*}$

Table 1. Mothers of eutrophic and overweight children of high and low-income brackets according to the result of the Beck Depression Inventory.

\begin{tabular}{|c|c|c|c|c|c|c|c|c|}
\hline \multirow{2}{*}{ Children } & \multicolumn{4}{|c|}{ High-income bracket } & \multicolumn{4}{|c|}{ Low-income bracket } \\
\hline & with & $w / 0$ & Total & $\%$ with & with & $w / 0$ & Total & \% with \\
\hline Eutrophic & 1 & 29 & 30 & 3.3 & 13 & 17 & 30 & 43.3 \\
\hline Overweight & 3 & 27 & 30 & 10.0 & 8 & 22 & 30 & 26.7 \\
\hline Total & 4 & 56 & 60 & 6.7 & 21 & 39 & 60 & 35.0 \\
\hline
\end{tabular}

Chi-square test

$\chi^{2}=0.31$

(NS)

High vs. Low

Eutrophic

$\chi^{2}=13.41^{*}(p<0.001)$

high $<$ low

NS $=$ non-significant 
Table 4. Mothers of eutrophic and overweight children of low and high-income brackets according to result (adequate or compromised) of the evaluations of the Mother/ Child Bonding Assessment Protocol and of Beck Depression)

\begin{tabular}{|c|c|c|c|c|c|c|c|}
\hline \multicolumn{4}{|c|}{ Eutrophic of high-income bracket } & \multicolumn{4}{|c|}{ Eutrophic of low-income bracket } \\
\hline Bond & Adequate & Compromised & Total & Bond & Adequate & Compromised & Total \\
\hline Adequate & 10 & 0 & 10 & Adequate & 8 & 0 & 8 \\
\hline Compromised & 19 & 1 & 20 & Compromised & 9 & 13 & 22 \\
\hline Total & 29 & 1 & 30 & Total & 17 & 13 & 30 \\
\hline \multicolumn{4}{|l|}{ Mc Nemar test } & \multicolumn{4}{|l|}{ Mc Nemar test } \\
\hline \multicolumn{4}{|l|}{$p=0.0000$} & \multicolumn{4}{|l|}{$p=0.0019$} \\
\hline \multicolumn{4}{|c|}{$\%$ of agreement $11 / 30=36.7 \%$} & \multicolumn{4}{|c|}{$\%$ of agreement $21 / 30=70.0 \%$} \\
\hline \multicolumn{4}{|c|}{$\%$ of disagreement $19 / 30=63.3 \%$} & \multicolumn{4}{|c|}{$\%$ of disagreement $9 / 30=30.0 \%$} \\
\hline \multicolumn{4}{|c|}{ Mothers of high-income overweight children } & \multicolumn{4}{|c|}{ Mothers of low-income overweight children } \\
\hline Bond & Adequate & Compromised & Total & Bond & Adequate & Compromised & Total \\
\hline Adequate & 8 & 0 & 8 & Adequate & 9 & 2 & 11 \\
\hline Compromised & 19 & 3 & 22 & Compromised & 13 & 6 & 19 \\
\hline Total & 27 & 3 & 30 & Total & 22 & 8 & 30 \\
\hline \multicolumn{4}{|l|}{ Mc Nemar test } & \multicolumn{4}{|l|}{ Mc Nemar test } \\
\hline \multicolumn{4}{|l|}{$p=0.0000$} & \multicolumn{4}{|l|}{$p=0.0036$} \\
\hline \multicolumn{4}{|c|}{$\%$ of agreement $11 / 30=36.7 \%$} & \multicolumn{4}{|c|}{$\%$ of agreement $15 / 30=50 \%$} \\
\hline \multicolumn{4}{|c|}{$\%$ of disagreement $19 / 30=63.3 \%$} & \multicolumn{4}{|c|}{$\%$ of disagreement $15 / 30=50 \%$} \\
\hline
\end{tabular}

\section{DISCUSSION}

In this study, there was no significant difference in the results between the presence of depression and level of schooling, marital status, occupation, and maternal nutritional status or between the mother/child bond and the variables analyzed, although the bond was significantly compromised in the entire sample.

However, in associating variables (presence of depression in mothers of high- and low-income brackets and nutritional status), it was noted that those with high economic conditions showed less depression than those of low-income bracket. This may easily be understood, since it is known that a precarious economic condition may be a factor of risk to the well-being of families, generating suffering for mothers, besides interfering negatively in verbal and cognitive stimulation, which results from a good mother/child relationship ${ }^{(5,10,16)}$.

Nevertheless, the association between the bond and the mothers' economic condition showed no significant result, that is, income was not a determining factor for a good mother/child bond. The fact of the mother having better economic conditions does not determine the quality of her relationships. Good financial conditions, however, may help in the provision of the family's basic needs, which can generate in the mother a feeling of physical and emotional comfort. In addition, it enables her to have better access to medical care, when necessary. To become ill without having the resources to care for oneself and one's children is a stress factor that can lead to depression. It can be assumed, then, that the good financial status allowed mothers to invest in good quality of life, thus justifying the result found ${ }^{(17)}$.
Another finding of the present study refers to mothers with three or more children showing more depression than mothers with less than three children. It can be supposed that depression found may be tied to stress and concerns with rearing one's children satisfactorily. This concern is always dependent on financial conditions. Today, regardless of the economic bracket, the number of women who work outside the home to guarantee the support of their families has grown expressively. On the one hand, women feel responsible for tending to their homes, their children, and their husbands, and are constantly trying to conciliate activities outside and inside the home ${ }^{(18)}$. On the other hand, their partners do not always show appreciation for their efforts, which leads to feelings of abandonment, loneliness, and possibly, depression. Depressed mothers show less affection, play less with their children, are more hostile, dissatisfied, and adopt more punitive and controlling attitudes with their children; they may become more introverted and even insensitive to their children's health and safety ${ }^{(19)}$. Actually, mothers with compromised bonding with their child, lack of support from their companion, stress due to the work load, with three or more children to tend to, caring for their physical/psychological needs and still having to care for themselves, their homes, and their husbands, probably will be less available emotionally. The pleasure that they could have in their affective relationships, especially with their children, is transformed into obligation as a result of an accumulation of tasks, and this is one of the factors that may justify the result found; additionally, the fact that most mothers have a companion is not sufficient, in and of itself, for them to feel understood, loved, and valued $\left({ }^{20,21}\right)$. 
On the other hand, mothers with less than three children (and less depressed) may have found more time to dedicate to pleasurable activities and to themselves, which favors this relationship. They also may have encountered more room for tending to their relationship with their partner and to their own emotional lives ${ }^{(19)}$. Possibly, the points mentioned may be an explanation for the results obtained in the present investigation.

Also found in this study, were mothers under 30 years of age who displayed more depression than mothers 30 years of age or older. One of the possible explanations may be the fact that they had not been adequately stimulated by their own mothers or that they were unable to establish a safe affective bond, which may have been reflected negatively in their feeling of security when facing difficulties in life. Knowing that maternal depression interferes in childhood development and may cause negative effects, mothers under 30 years of age, possibly daughters of depressed mothers, are more susceptible to affective disorders and a negative self-image, besides feeling incompetent as mothers, and, consequently, they also evaluate their children in a negative way ${ }^{(3,19,20)}$. In contrast mothers 30 years of age or more showed less depression. Maturity brought by life experience may have made them feel more effective. Nevertheless, it is possible that the genesis of this feeling is found in the first affective relationship, when their self-confidence and autonomy received the necessary investment for a healthy development ${ }^{(4,20)}$. These are possibilities that may give meaning to the results obtained.

As to the mother/child bonding study, no significant result was found among the variables analyzed, although, as mentioned, the bond was significantly compromised in all mothers. Regardless of economic and nutritional status, the mothers displayed greater impairment in this bonding than in the presence of depression. One of the hypotheses that can be made is in regard to the mother's experiences during her own childhood, of situations of privation of affection from her own mother, which interfered in her capacity to adequately perform her own maternal roles. The quality of affection and behaviors adopted by parents significantly influences those to be adopted by their children in their current and future relationships, and which will be transmitted from generation to generation (21). It is probable, therefore, that the mothers in this sample had relational problems with their own mothers, which compromised not only their own bonding with their mothers, but with their children as well, and this could be one of the reasons for the given finding.

It is not possible, however, to avoid discussing the fact that no association was found in the statistical analysis between the compromised bond and the presence of depression. The mother who is impaired in her bonding with her child might not have had, among other aspects, positive parental models that allowed her to develop a secure bond with her child. Perhaps she experiences more moments of tension than moments of pleasure when she is with the child, which may be reflected in other factors of her life, such as her marital relationship. If one considers that it is in family relations that meaning for our emotional experiences is formed, on which one can test one's ability to perform well the role of parenthood, which is a place where feelings of fulfillment and failure are most evident, both in the man and in the woman ${ }^{(22)}$, then it is unlikely that this mother will be insensitive to a lack of harmony in her own home, unless she is depressed. In this condition, she may deny the child her affection, thus hindering good bonding between the two and the child's healthy development ${ }^{(8-10,17-23)}$.

The fact that no association was found between the compromised bond and depression might be justified by the fact that many women do not fit the diagnostic criteria for depression, as per the Diagnostic and Statistical Manual of Mental Disorders - DSM$\mathrm{IV}^{(24)}$ and may present with symptoms that provoke a functional incapacity comparable to or worse than what is seen in clinical pictures with established chronicity. Such symptoms may be classified as Common Mental Disorders (CMD) ${ }^{(25)}$ and their prevalence is greater in women. The symptoms include insomnia or excessive sleep, irritability, fatigue, agitation, memory and concentration difficulties, feeling of unworthiness or guilt, and somatic complaints. Even presenting with this picture, there is no search for the necessary treatment, and when it occurs, the patients may be underdiagnosed due to the variation in presentation and intensity of symptoms. Many times they are neglected by the women herself, by her husband, or by family members, who attribute the symptoms to being tired due to housework and taking care of the children ${ }^{(26)}$.

In this sense, the result found is comprehensible. It is probable that the mothers in this sample, who presented with compromised bonding, had also presented with CMD. Maybe, if the Self-Reporting Questionnaire, SRQ $\left({ }^{27)}\right.$ had been applied, a screening instrument for non-psychotic mental disorders, it would have been possible to positively associate CMD and compromised bonding. We do not believe that this represents a limitation to this study, since it answers important questions and raises other equally intriguing issues that merit and justify continuous scientific investigation.

\section{CONCLUSION}

We gather from the results found that the presence of maternal depression and of compromised mother/child bonding, even though not incapacitating in some cases for infant care, may negatively interfere in the child's social, 
cognitive, physical, and psychological development, as well as in its future affective relationships.

\section{ACKNOWLEDGMENTS}

\section{The Coordination for the Improvement of Higher Education Personnel (CAPES).}

\section{REFERENCES}

1. Bowlby J. Apego - a natureza do vínculo. São Paulo: Martins Fontes; 2002.

2. Bowlby J. Some pathological processes set in train by early mother-child separation. F Ment Sci. 1953;99(415):265-72.

3. Spitz RA. 0 primeiro ano de vida. São Paulo: Martins Fontes; 1983.

4. Klaus MH, Kennel JH. Pais/bebê: a formação do apego. Porto Alegre: Artes Médicas; 1992.

5. Cicco MF, Paiva MC, Gomes IC. Família e conjugalidade: 0 sintoma dos filhos frente à imaturidade do casal parental. Psicologia Clínica. 2005;17(2):53-63.

6. Piccinini CA, Moura MLS, Ribas AFP, Bosa CA, Oliveira EA, Pinto EB, et al. Diferentes perspectivas na análise da interação pais-bebê/criança. Psicologia Reflexão e Crítica. 2001;14(3):469-83.

7. Fleck $A C$, Wagner $A$. A mulher como a principal provedora do sustento econômico familiar. Psicol Estud. 2003;8(no. esp.):31-8.

8. Gomes IC, Paiva MLSC. Casamento e família no século XXI: possibilidade de holding. Psicol Estud. 2003;8(no. esp):3-9.

9. Nóbrega FJ, Campos AL, Nascimento CFL. Distúrbios nutricionais e fraco vínculo mãe/filho. Rio de Janeiro: Revinter; 2000.

10. Colugnati F, Taddei CJAA. Propriedades psicométricas do Instrumento de Avaliação do Vínculo Mãe/Filho. In: Nóbrega FJ, organizador. Distúrbios da nutrição na infância e na adolescência. Rio de Janeiro: Revinter; 2007. p. 151-65.

11. Nóbrega FJ. Vínculo mãe/filho. Rio de Janeiro: Revinter; 2004.

12. Programa Einstein na Comunidade de Paraisópolis [Internet]. Brasil: Sociedade Beneficente Israelita Brasileira [updated 2007; cited 2009 Feb 17]. Available at: http://www.einstein.br/responsabilidade-social/Programas-Comunitarios/
Programa-Einstein-na-Comunidade-Paraisopolis/Paginas/programa-einsteinna-comunidade-paraisopolis.aspx

13. Patton M. Qualitative evaluation and research methods. California: Sage Publications, Newbury Park; 1990.

14. Goreinstein C, Andrade L, Vieira Filho AHG, Tung TC, Artes R. Psychometric properties of the Portuguese version of the Beck Depression Inventory on Brazilian College Students. J Clin Psychol. 1999;55(5):553-62.

15. World Health Organization. Obesity. Preventing and managing the global epidemic. Geneva: WHO; 1998.

16. Siegel S, Castellan JRNJ. Estatística não paramétrica para ciências do comportamento. Porto Alegre: Artmed; 2006.

17. Weber LND, Prado PM, Viezzer AP, Brandenburg OJ. Identificação de estilos parentais: o ponto de vista dos pais e dos filhos. Psicol Reflex Crit. 2004;17(3):323-31.

18. Winnicott DW. Os bebês e suas mães. São Paulo: Martins Fontes; 1994.

19. Paniz VMV, Fassa AG, Silva MC. Conhecimento sobre anticoncepcionais em uma população de 15 anos ou mais de uma cidade do sul do Brasil. Cad Saúde Pública. 2005;21(6):1747-60.

20. Brum EHM, Schermann L. 0 impacto da depressão materna nas interações iniciais. Psico. 2006;37(2):151-8.

21. Cruz EBS, Simões GL, Cury AF. Rastreamento da depressão pós-parto em mulheres atendidas pelo programa de Saúde da Família. Rev Bras Ginecol Obstet 2005;27(4):181-188.

22. Brazelton TB, Cramer BG. As primeiras relações. São Paulo: Martins Fontes; 1992.

23. Bretherton, I. The origins of attachment theory: John Bowlby and Mary Ainsworth. Developmental Psychology 1992;28:759-775.

24. DSM IV - Manual diagnóstico e estatístico de transtornos mentais. Trad Dayse Batista. Porto Alegre: Artes Médicas; 1995.

25. Maragno L, Goldbaum M, Gianini RJ et al. Prevalência de transtornos mentais comuns em populações atendidas pelo Programa Saúde da Família (QUALIS) no Município de São Paulo, Brasil. Cad Saúde Pública 2006;22(8):1639-1648.

26. Carvalhaes MABL, Benício MHA. Capacidade materna de cuidar e desnutrição infantil. Rev Saúde Pública 2002;36(2):188-97.

27. World Health Organization. AUser's Guide to the Self Reporting Questionnaire (SRO), WHO/MNH/PSF/98.1. WHO, Geneva, 1994. 